\title{
Thromboembolism in a Patient with a Left Ventricular Aneurysm
}

\author{
Muhammad Akbar Baig, Fatima Najeeb, Shahan Waheed, Nadeem Ullah Khan \\ Department of Emergency Medicine, Aga Khan University Hospital, Karachi, Pakistan
}

\begin{abstract}
Idiopathic aneurysms involving the left ventricle are considered very rare, and in a majority of instances, they are asymptomatic. In a minority of patients, they may present with cardiac rupture, cardiac tamponade, ventricular arrhythmias, and sudden death. We describe the case of a 21-year-old male patient who was hospitalized for altered mentation and critical left lower limb ischemia because of acute embolic events. Transthoracic echocardiography demonstrated a left ventricular aneurysm and a reduced ejection fraction. Similarly, cardiac computed tomography showed a large left ventricular aneurysm with mobile vegetations representing thrombi. He was managed with therapeutic anticoagulation and recovered uneventfully.

Keywords: Thromboembolism, aneurysm, left ventricle, transthoracic echocardiography
\end{abstract}

\section{Introduction}

A left ventricular aneurysm (LVA) refers to a dyskinetic area of the ventricular wall with a broad neck; this distinguishes it from a pseudoaneurysm (1). Pathologically, the wall of a true LVA is thinned out in comparison to the rest of the wall of the left ventricle and is usually composed of fibrous tissue, necrotic muscle, and sometimes, viable myocardium. LVAs can be congenital or acquired. The congenital variety is potentially lethal and develops as a result of a defective ventricular wall (2). The acquired types can be differentiated into cardiac and non-cardiac types where they are most commonly attributed as a result of coronary artery disease. Other various causes include cardiomyopathy, myocarditis, trauma, cardiac sarcoidosis, or Chagas disease (3). LVAs without an established cause are referred to as idiopathic (4). Favored sites of involvement include the anterior or anterolateral wall territory. Well-documented complications include thrombus formation, cardiac output impairment, aneurysmal rupture, and ventricular arrhythmias (5). Mortality in patients with LVA is up to six-times higher than that in patients without aneurysms (6). Death is often sudden and is most commonly related to the high incidence of ventricular tachyarrhythmias as a result of LVAs (7).

\section{Case Presentation}

A 21-years-old male presented to a hospital with a 1-day history of left lower extremity pain, which was followed by an altered mental status occurring in the last $4 \mathrm{~h}$ associated with a single episode of non-bilious, non-projectile vomiting. The prior medical, surgical, and family history was unremarkable. Upon presentation, he had a Glasgow Coma Scale (GCS) of 12/15 (E3V3M6), and a physical examination revealed a pale, pulseless, and poikilothermic left lower extremity. His baseline 12-lead electrocardiogram (ECG) demonstrated left ventricular hypertrophy with inverted T waves in leads II, III, aVF, and V5-6 (Figure 1). Laboratory investigations of blood samples were sent, which included a complete blood count; blood glucose, BUN, creatinine, and serum Electrolytes levels; and coagulation profile, and the results were within normal ranges. The chest X-ray was unremarkable. He underwent CT angiography of lower extremities (Figure 2), which revealed occlusion of the left common femoral artery. Immediate anti-coagulation with IV heparin and activated partial thromboplastin time monitoring were started. Because of his altered mentation, MRI of the brain was performed, which demonstrated multiple bilateral infarcts involving the frontal and parietal regions and thalami, suggesting an embolic phenomenon. A transthoracic

Correspondence to: Muhammad Akbar Baig e-mail: dr_akbar2007@hotmail.com 


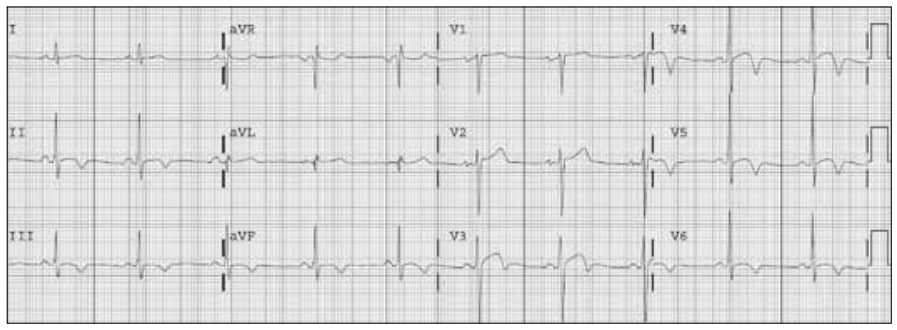

Figure 1. Twelve-lead electrocardiogram demonstrating left ventricular hypertrophy with inverted T waves in leads II, III, aVF, and V5-6

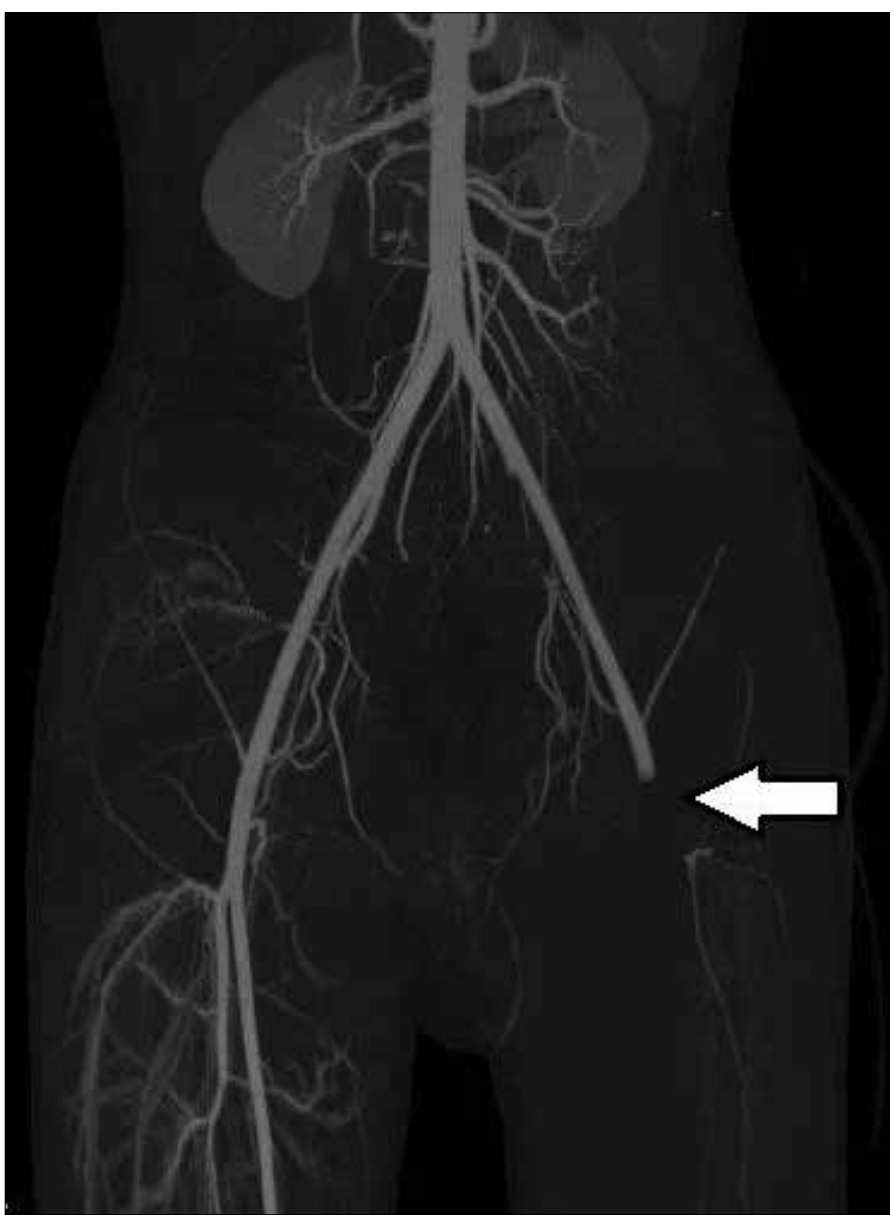

Figure 2. Abrupt cutoff/complete occlusion of the left common femoral artery noted. The left internal iliac artery also appears occluded just distal to its origin

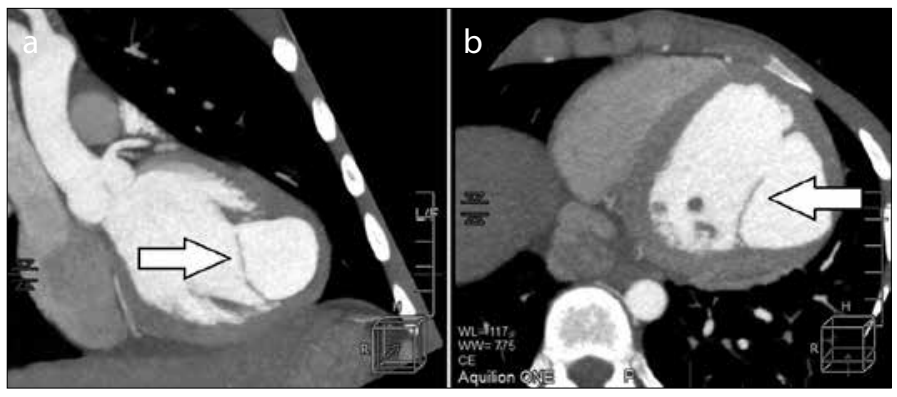

Figure 3. a, b. CT coronary angiogram demonstrating a large left ventricular aneurysm involving the mid-to-distal inferolateral segments and large mobile filamentous structures arising from the junction of normal and aneurysmal wall representing thrombi echocardiogram was performed, which showed severe global hypokinesia with an ejection fraction of $20 \%$ and a mid-to-distal posterolateral wall aneurysm, with suggestion of further advance imaging. Cardiac CT showed a large LVA involving the mid-to-distal inferolateral segments and large mobile filamentous structures arising from the junction of normal and aneurysmal wall, representing thrombi. The coronaries were normal (Figure 3). During the hospital stay, the patient underwent above-knee amputation of the left side. His anti-coagulant was progressively modified to enoxaparin and he was started on beta blockers. He recovered uneventfully and was discharged in a stable condition; he was advised to visit the hospital for regular follow-ups.

\section{Discussion}

Left ventricular aneurysms are rare lesions that most commonly occur in the African population (8). They seem to occur as a result of a junctional defect between the cardiac muscle and the fibrous structure of the heart. The anatomy of the lesion can be complicated and has varying sizes, ranging from a few millimeters to several centimeters (9). Generally, a routine physical examination can fail to diagnose LVAs, unless there is calcification involving the aneurysmal wall (10). Progressive aneurysmal growth can cause eventual loss of support to the mitral apparatus, resulting in mitral regurgitation and cardiac failure. Currently, echocardiography serves as the most accurate tool for identification (11). The typical location of the aneurysm and the absence of coronary artery disease on angiography confirm a diagnosis of LVA.

Patients with LVAs can present with a variety of symptoms such as recurrent arterial emboli $(12,13)$, angina (14), congestive heart failure (15), ventricular tachyarrhythmias, and sudden cardiac death. The treatment and prognosis of LVAs are largely dependent on their size and location and on the degree of valvular involvement, functional class of congestive heart failure, and presence of ventricular tachyarrhythmias. Therefore, treatment can range from antiarrhythmic drugs (16) to VT ablation (17), implantation of an ICD (18), or aneurysmectomy (19). However, there are no long-term follow-up studies comparing the different management strategies.

\section{Conclusion}

Left ventricular aneurysms are rare lesions that should be suspected in patients presenting with a clinical history of embolism, ventricular arrhythmias, and no cardiovascular disease. For emergency physicians, this should be considered in the differential diagnosis in patients presenting with multiple thromboembolisms involving different sides. Such patients should undergo echocardiography early in the ED to identify the condition.

Informed Consent: Informed consent was taken from the patient prior to writing the case report.

Peer-review: Externally peer-reviewed.

Conflict of Interest: No conflict of interest was declared by the authors.

Financial Disclosure: The authors declared that this study has received no financial support. 


\section{References}

1. Konen E, Merchant N, Gutierrez C, Provost Y, Mickleborough L, Paul NS, et al. True versus false left ventricular aneurysm: differentiation with MR imaging--initial experience. Radiology 2005; 236: 65-70. [CrossRef]

2. Papagiannis J, Van Praagh R, Schwint O, D'Orsogna L, Qureshi F, Reynolds $J$, et al. Congenital left ventricular aneurysm: clinical, imaging, pathologic, and surgical findings in seven new cases. Am Heart J 2001; 141:491-9. [CrossRef]

3. Ba'albaki HA1, Clements SD Jr. Left ventricular aneurysm: a review. Clin Cardiol 1989; 12: 5-13. [CrossRef]

4. Paul M, Schäfers M, Grude M, Reinke F, Juergens KU, Fischbach R, et al. Idiopathic left ventricular aneurysm and sudden cardiac death in young adults. Europace 2006; 8: 607-12. [CrossRef]

5. Gorlin R, Klein MD, Sullivan JM. Prospective correlative study of ventricular aneurysm: Mechanistic concept and clinical recognition. Am J Med 1967; 42: 512. [CrossRef]

6. Campeau RL. Natural history of saccular aneurysms of the left ventricle. J Thorac Cardiovasc Surg 1979; 77: 57.

7. Cannom DS, Prystowsky EN. Management of ventricular arrhythmias: detection, drugs, and devices. JAMA 1999; 281: 172-9. [CrossRef]

8. Beck W, Schrire V. Idiopathic mitral subannular left ventricular aneurysm in the Bantu. Am Heart J 1969; 78: 28-33. [CrossRef]

9. Antunes MJ. Submitral left ventricular aneurysms. Correction by a new transatrial approach. J Thorac Cardiovasc Surg 1987; 94: 241-5.

10. Szarnicky RJ, De Leval MR, Stark J. Calcified left ventricular aneurysm in a 6-year-old Caucasian boy. Br HeartJ 1981; 45: 464-6. [CrossRef]

11. Davis MD, Caspi A, Lewis BS, Milner S, Colsen PR, Barlow JB. Two-dimensional echocardiographic features of submitral left ventricular aneurysm. Am Heart J 1982; 103: 289-90. [CrossRef]
12. Nabavi DG, Arato S, Droste DW, Schulte-Altedorneburg G, Kemény V, Reinecke $\mathrm{H}$, et al. Microembolic load in asymptomatic patients with cardiac aneurysm, severe ventricular dysfunction, and atrial fibrillation. Clinical and hemorheological correlates. Cerebrovasc Dis 1998; 8: 21421. [CrossRef]

13. Esposito F, Renzulli A, Festa M, Cerasuolo F, Caruso A, Sarnicola P, et al. Submitral left ventricular aneurysm. Report of 2 surgical cases. Tex Heart Inst J 1996; 23: 51-3.

14. Bouramoue C, Nkoua JL, Gombet T, Kimbally-Kaky G, Ekoba J. Idiopathic subvalvular aneurysm of the left ventricle. Anatomical, clinical and development characteristics. Apropos 13 cases. Ann Cardiol Angeiol (Paris) 1995; 44: 7-13.

15. Papagiannis J, Van Praagh R, Schwint O, D'Orsogna L, Qureshi F, Reynolds $J$, et al. Congenital left ventricular aneurysm: clinical, imaging, pathologic, and surgical findings in seven new cases. Am Heart J 2001; 141: 491-9. [CrossRef]

16. Mestroni L, Morgera T, Miani D, Pinamonti B, Sinagra G, Tanganelli P, et al. Idiopathic left ventricular aneurysm: a clinical and pathological study of a new entity in the spectrum of cardiomyopathies. Postgrad Med J 1994; 70(Suppl 1): S13-20.

17. Ouyang $F$, Antz $M$, Deger FT, Bänsch $D$, Schaumann A, Ernst $S$, et al. An underrecognized subepicardial reentrant ventricular tachycardia attributable to left ventricular aneurysm in patients with normal coronary arteriograms. Circulation 2003; 107: 2702-9. [CrossRef]

18. Rimailho A, Cabrol C, Soyer R, Letac B, Berteau P, Fouchard J, et al. Idiopathic aneurysm of the left ventricle. Apropos of 4 cases operated on with success. Arch Mal Coeur Vaiss 1981; 74: 443-51.

19. Rajasinghe HA, Lorenz HP, Longaker MT, Scheinman MM, Merrick SH. Arrhythmogenic ventricular aneurysms unrelated to coronary artery disease. Ann Thorac Surg 1995; 59: 1079-84. [CrossRef] 